\title{
Duloxetine in the management of chronic musculoskeletal pain
}

This article was published in the following Dove Press journal:

Therapeutics and Clinical Risk Management

18 June 2012

Number of times this article has been viewed

\author{
Howard S Smith' \\ Eric J Smith² \\ Benjamin R Smith ${ }^{2}$ \\ 'Department of Anesthesiology, \\ Albany Medical College, Albany, NY; \\ ${ }^{2}$ The Pharmaceutical Research \\ Institute, Albany College of Pharmacy \\ and Health Sciences, Rensselaer, NY, \\ USA
}

Correspondence: Howard S Smith Department of Anesthesiology, Albany Medical College, 47 New Scotland Avenue, MC-I3I, Albany, NY, USA I 2208 $\mathrm{Tel}+\mathrm{I} 518262446$ I

Fax + I 5182624462

Email smithh@mail.amc.edu
Abstract: Chronic musculoskeletal pain is among the most frequent painful complaints that healthcare providers address. The bulk of these complaints are chronic low back pain and chronic osteoarthritis. Osteoarthritis is the most common form of arthritis in the United States. It is a chronic degenerative disorder characterized by a loss of cartilage, and occurs most often in older persons. The management of osteoarthritis and chronic low back pain may involve both nonpharmacologic (eg, weight loss, resistive and aerobic exercise, patient education, cognitive behavioral therapy) and pharmacologic approaches. Older adults with severe osteoarthritis pain are more likely to take analgesics than those with less severe pain. The pharmacologic approaches to painful osteoarthritis remain controversial, but may include topical as well as oral nonsteroidal antiinflammatory drugs, acetaminophen, duloxetine, and opioids. The role of duloxetine for musculoskeletal conditions is still evolving.

Keywords: pain, musculoskeletal, duloxetine, osteoarthritis, low back, serotonin-norepinephrine reuptake inhibitor

\section{Introduction}

The majority of chronic musculoskeletal pain complaints are largely related to chronic low back pain and osteoarthritis. Chronic low back pain (CLBP) and osteoarthritis (OA) of any joint are highly prevalent occurring in $>50 \%$ of United States adults aged $>60$ years. Opioids are prescribed more frequently for CLBP and OA than for any other noncancer pain, and the judicious use of opioids is recommended by treatment guidelines for the management of CLBP and OA pain. ${ }^{1}$

The number of patients who are prescribed opioids for chronic noncancer pain is increasing, representing more than one-third of all patients with chronic noncancer pain enrolled in a commercially insured national population. ${ }^{2,3}$ In this population, the most common etiologies of chronic noncancer pain for which patients received opioids were OA of proximal and peripheral joints and CLBP, which may also be caused by OA of the spine. ${ }^{2}$

$\mathrm{OA}$ and CLBP are among the most frequent causes of chronic noncancer pain and may be grouped together under chronic musculoskeletal disorders. OA and CLBP are often concurrent. Patients with OA of proximal and peripheral joints frequently have CLBP. ${ }^{4,5}$ Although OA and CLBP are both significantly associated with obesity, cardiovascular disease, and cardiovascular risk factors, ${ }^{6-9}$ the presence of $\mathrm{OA}$ in young adults predicts elevated risk of cardiovascular disease independent of obesity. ${ }^{10}$ The associations between chronic pain conditions, cardiovascular disease, 
and cardiovascular risk factors may influence treatment decisions for the management of OA and CLBP.

Treatment guidelines for the management of CLBP ${ }^{11-13}$ and OA pain ${ }^{14-16}$ all state that efforts to manage pain and improve function should be multimodal and begin with physical measures such as rehabilitation and exercise. Nonpharmacologic modalities include advice on effective self-care and maintenance of appropriate activity and exercise; behavioral therapy and progressive relaxation; physical interventions, such as spinal manipulation (for CLBP), application of heat, use of orthotic devices (eg, back or knee braces), transcutaneous electrical nerve stimulation (for OA), and acupuncture; and multidisciplinary therapy or interdisciplinary rehabilitation. ${ }^{11,16}$ Nonpharmacologic treatments may be of particular importance in patients with CLBP for whom psychosocial factors such as depression, passive coping strategies, job dissatisfaction, greater disability, and somatization may be more predictive of poor outcome than pain intensity. ${ }^{11,17}$

When pharmacotherapy is required, acetaminophen is typically recommended as a first-line therapy for OA pain ${ }^{15,16}$ and CLBP. ${ }^{11}$ Acetaminophen is less effective than nonsteroidal antiinflammatory drugs (NSAIDs) ${ }^{8,18}$ and has shown the potential for hepatic toxicity at doses of $>4 \mathrm{~g} /$ day. ${ }^{9}$ In fact, the United States Food and Drug Administration is considering reducing the maximum dose to $3250 \mathrm{mg} /$ day based on the clinical observation that the margin between the maximum recommended dose and a potentially toxic dose is lower than with other medications. ${ }^{19}$ The next step in pharmacotherapy is frequently an oral NSAID, which may provide adequate effectiveness for mild-to-moderate CLBP or OA pain. ${ }^{20,21}$ However, oral NSAIDs are associated with dose-related risks of gastrointestinal, ${ }^{22}$ cardiovascular, ${ }^{23}$ and renal $^{24}$ adverse events (AEs). NSAIDs also have significant potential for interaction with drugs commonly prescribed to patients with heart disease, most notably antihypertensive drugs, ${ }^{25}$ warfarin, ${ }^{26}$ and low-dose cardioprotective aspirin. ${ }^{27}$ Nonetheless, for patients with heightened risk of AEs with other treatments, a trial of nonselective NSAIDs with a proton pump inhibitor or celecoxib may be warranted.

Although several guidelines recommend oral NSAIDs as a first-line therapy in selected patients, ${ }^{11,16}$ American Geriatric Society guidelines for the management of persistent pain in older patients and the National Institute for Health and Clinical Excellence guidelines for OA suggest that NSAIDs should be avoided when possible. ${ }^{14,28}$

Both the National Institute for Health and Clinical Excellence guidelines and OA Research Society International guidelines for the management of hand and knee OA recommend topical NSAIDs over oral NSAIDs. Topical NSAIDs produce high drug concentrations in the treated joint with lower systemic NSAID exposure compared with oral NSAIDs $^{29}$ and have demonstrated efficacy in patients with hand and knee OA pain. ${ }^{30-32}$ Topical NSAID trials have not been of sufficient length to conclusively gauge the long-term risk of serious AEs compared with oral NSAIDs; however, in 12-week trials, topical formulations of diclofenac ${ }^{31-33}$ resulted in fewer gastrointestinal AEs, including bleeding events, and fewer discontinuations due to AEs than were reported with celecoxib, oral diclofenac, and naproxen in the SUCCESS (Successive Celecoxib Efficacy and Safety Studies) trial. ${ }^{34}$ Topical NSAIDs are not indicated for and have not been studied for CLBP. Although only approved for the treatment of postherpetic neuralgia, ${ }^{35}$ the topical lidocaine $5 \%$ patch has shown efficacy in several trials of patients with OA of the $\mathrm{knee}^{36,37}$ and nonradicular CLBP, ${ }^{38-40}$ and may be considered to supplement other therapies as part of the multimodal approach to these painful conditions.

With adequate response to oral analgesics, intraarticular injections of hyaluronic acid or depocorticosteroids are recommended in current OA guidelines. ${ }^{15,16}$ In patients with CLBP, epidural or transforaminal corticosteroid injections are recommended for patients with suspected radiculopathy. ${ }^{11}$ In patients with severe or progressive OA, surgical replacement has proven to be successful for the knee and hip joints, ${ }^{41,42}$ but not for the much smaller joints of the hand. ${ }^{43,44}$ Figure 1 is a biased nonconsensus algorithm for a topical/ oral pharmacologic approach to the treatment of painful OA before interventional approaches are used. This algorithm of the management of OA should not be viewed as a fixed and "concrete" treatment blueprint, but rather as a flexible dynamic guide to assist busy clinicians. Although duloxetine monotherapy is shown as a potential second-line pharmacologic agent, it is not meant to discourage clinicians from utilizing an NSAID first in any particular patient, but rather to suggest a loose framework in which to consider choosing various therapeutic agents. The authors chose to put duloxetine before NSAIDs or tramadol in the algorithm largely due to the potential adverse effects of NSAIDs (eg, peptic ulcer disease, gastrointestinal bleeding, renal insult) and tramadol (eg, seizures, opioid-like adverse effects such as the potential for tramadol misuse, abuse, addiction, ${ }^{45-49}$ or dose-related opioid physical dependency). ${ }^{50,51}$

The most recent OA Research Society International guidelines for the management of OA of the knee and hip recommend opioids for pain reduction, citing robust effect 


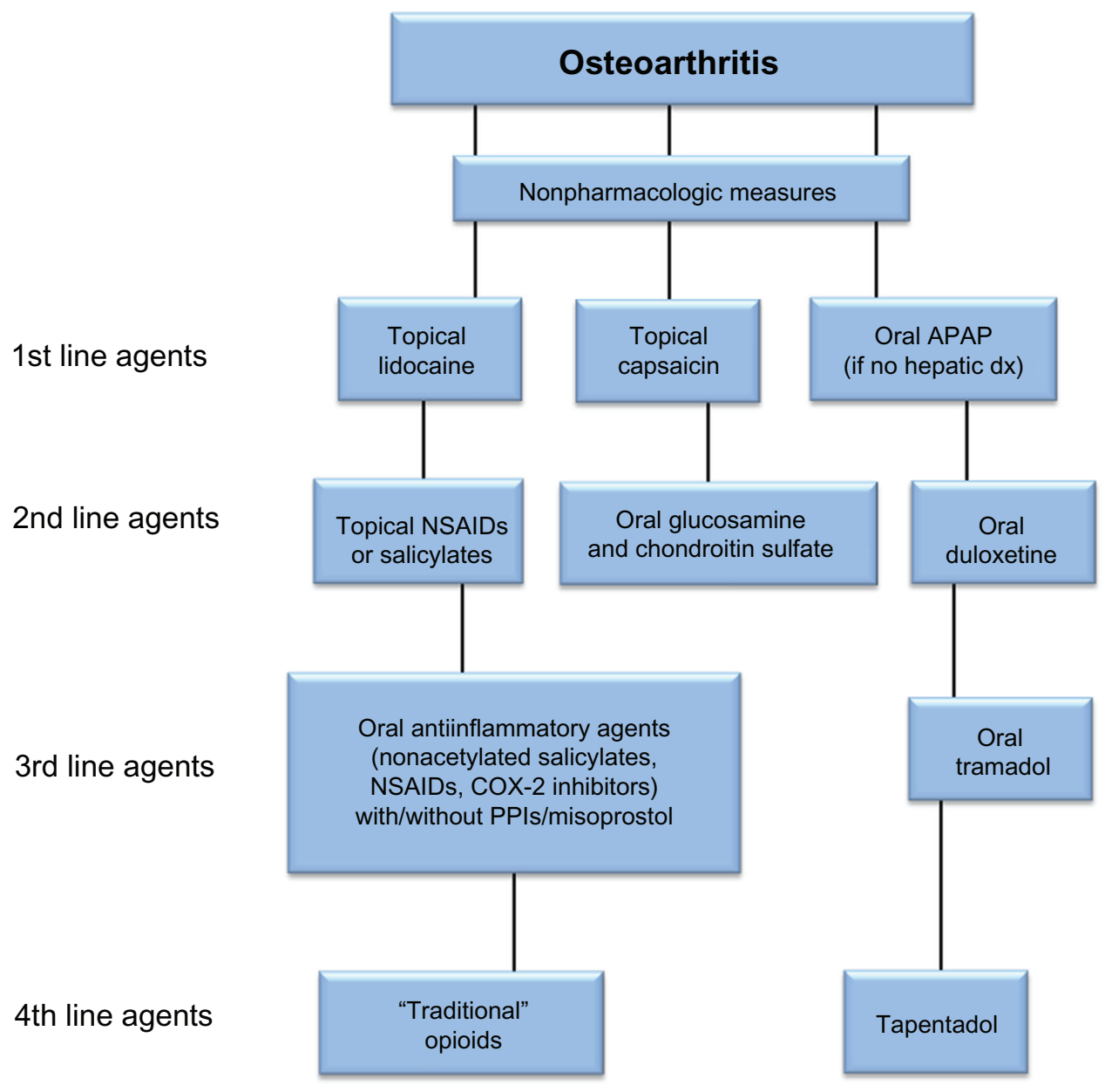

Figure I Algorithm for topical/oral pharmacologic approach to the treatment of painful osteoarthritis.

Abbreviations: APAP, acetaminophen; dx, doxorubicin; NSAID, nonsteroidal antiinflammatory drug; PPI, proton pump inhibitor.

size of 0.78 compared with 0.44 for topical NSAIDs, 0.29 for oral NSAIDs, and just 0.14 for acetaminophen. ${ }^{52}$ According to these guidelines, the most likely AEs with opioids include constipation, nausea, vomiting, dizziness, and somnolence, which are less serious than the potential AEs listed for oral NSAIDs (gastrointestinal perforations, ulcers, bleeding, and myocardial infarction). ${ }^{52}$ Guidelines from the American Pain Society in conjunction with the American Academy of Pain Medicine for the management of CLBP, ${ }^{11}$ and separate National Institute for Health and Clinical Excellence guidelines for the management of OA and CLBP, ${ }^{14,53}$ recommend long-term opioid therapy when anticipated benefits outweigh assessed risks for the management of severe pain that does not respond (or is unlikely to respond) to acetaminophen or NSAIDs or when NSAIDs are contraindicated. The European League Against Rheumatism guidelines for the management of hand OA state that the efficacy and safety of "weak opioids" (opioids for mild to moderate pain), such as codeine or tramadol, need more study in randomized controlled trials, ${ }^{15}$ whereas guidelines developed by the European Cooperation in Science and Technology B13 Working Group recommend both "weak and strong opioids" (opioids for mild to moderate pain [score of 5-10 on Numerical Rating Scale-11] and opioids for moderate to severe pain [score of 6-10 on Numerical Rating Scale-11]) for patients with CLBP, but state that further clinical data are needed to strengthen the recommendation for "strong opioids" (opioids for moderate to severe pain).${ }^{54}$ The American Geriatric Society guidelines recommend opioids in selected older patients with persistent pain, observing that the risk of addiction is low in older patients without a history of abuse, whereas the risk of NSAID-related gastrointestinal, cardiovascular, and renal AEs increases with age. ${ }^{28}$

\section{Pharmacologic overview of duloxetine}

Duloxetine is classified pharmacologically as a serotoninnorepinephrine reuptake inhibitor which possesses high 
inhibition constant, $\mathrm{K}_{\mathrm{i}}$, values for monoamine transporters (eg, serotonin and norepinephrine transporters). ${ }^{55}$ The inhibition constant, $\mathrm{K}_{\mathrm{i}}$, value reflects the potency of an inhibitor compound as the tightness affinity of binding to the monoamine transporter. ${ }^{55}$ Duloxetine inhibits serotonin reuptake significantly more than norepinephrine reuptake (in an approximate 10:1 ratio). ${ }^{56}$ Duloxetine is the $(+)-(\mathrm{S})$ isomer of the racemic mixture with structural similarities to both fluoxetine and atomoxetine. ${ }^{55}$ It possesses a secondary amine structure unlike venlafaxine, the first approved serotonin-norepinephrine reuptake inhibitor, which possesses a tertiary amine structure. ${ }^{55}$ Duloxetine is approved by the Food and Drug Administration for the following uses: fibromyalgia, diabetic neuropathic pain, major depressive disorder, generalized anxiety disorder, ${ }^{57}$ and chronic musculoskeletal disorder.

Duloxetine is available in delayed-release enteric-coated capsules. ${ }^{55}$ The delayed-release formulation prevents dissolution in acidic conditions $(\mathrm{pH}<5.5)$ such as those in the stomach, but allows for immediate release and rapid absorption at the $\mathrm{pH}$ in the small intestine. ${ }^{58}$ Duloxetine exhibits a peak effect on platelet serotonin reuptake at 4-6 hours. Its inhibition persists for a duration of action of 7 days. ${ }^{55}$ The maximum plasma concentration $47 \mathrm{ng} / \mathrm{mL}$ (40 mg twice-daily dosing) is achieved 6 hours after a postprandial dose. ${ }^{59,60}$ The pharmacokinetics of duloxetine exhibit linearity and the steady-state concentration is reached in approximately 3-5 days. ${ }^{57}$ Its absorption and bioavailability are demonstrated to be 30\%-80\% (average about 50\%). ${ }^{59,60}$ Duloxetine exhibits a high degree of protein binding (90\%), and binds primarily to albumin and alpha-1 acid glycoprotein. ${ }^{55}$

Duloxetine has a usual half-life of $8-17$ hours. ${ }^{57}$ Its metabolic pathways include cytochrome P450 1A2 and 2D6 (CYP1A2 and CYP2D6). In addition to being a substrate, duloxetine may produce mild inhibition of CYP1A2 and moderate inhibition of CYP2D6. ${ }^{58}$ CYP2D6 exhibits genetic polymorphism and could potentially lead to the existence of poor, extensive, and ultraextensive metabolizers. ${ }^{55}$ Approximately $70 \%$ of duloxetine is renally excreted as metabolites, with $<1 \%$ as the parent compound. ${ }^{55}$ Metabolites found in plasma and urine include 4-hydroxy duloxetine glucuronide (primarily) and 5-hydroxy or 6-hydroxy duloxetine further metabolized (to catechol duloxetine and then) to 5-hydroxy, 6-methoxy duloxetine sulfate (or glucuronide), neither of which appear to be significantly pharmacologically active. ${ }^{61}$ Thus, patients with renal impairment (creatinine clearance of 30-80 mL/minute) should receive an initial lower dosage (ie, $20 \mathrm{mg}$ ) with the dose increased gradually thereafter. Approximately $20 \%$ of duloxetine is excreted in the feces, possibly representing hepatobiliary secretion. ${ }^{55}$

Patient demographic characteristics found to influence the pharmacokinetics of duloxetine include sex, smoking status, age, ethnicity, CYP2D6 genotype, hepatic function and renal function. Of these, only impaired hepatic function or severely impaired renal function (creatinine clearance of $<30 \mathrm{~mL} /$ minute) warrant specific warnings or dose recommendations. ${ }^{58}$ The effect of sex and smoking status on duloxetine exposure is attributable to CYP1A2 metabolism since these factors may affect the expression and activity of CYP1A2. ${ }^{62,63}$ CYP1A2 activity in women is lower than in men and this decrement in CYP1A2 activity has an impact on the metabolism of duloxetine, resulting in higher duloxetine systemic concentration in women compared with men. Smoking increases the expression of CYP1A2, and this increased expression is associated with a $30 \%$ decrease in duloxetine concentration in smokers compared with nonsmokers. The combined effect of sex and smoking status typically results in duloxetine concentrations for a male smoker that are 57\% lower than the concentrations in a female nonsmoker. ${ }^{58}$ In the presence of fluvoxamine, a potent CYP1A2 inhibitor, the oral bioavailability of duloxetine increased from $42.8 \%$ to $81.9 \%$. Pharmacodynamic study results indicate that duloxetine may enhance the effects of benzodiazepines. ${ }^{58}$ Activated charcoal significantly decreased duloxetine maximum concentration by approximately $32 \%$ and area under the curve by approximately $35 \%$, likely resulting from the binding of duloxetine to the activated charcoal when duloxetine was released into the gastrointestinal content. ${ }^{58}$

Abrupt discontinuation of any serotonin-norepinephrine reuptake inhibitor, including duloxetine, can cause a multitude of symptoms, including headache, dizziness, nightmares, irritability, paresthesia, and nausea/vomiting. ${ }^{55}$ Thus, it is recommended that this agent be decreased in small, decremental amounts over an extended period of time. There is also risk of serotonin syndrome (diaphoresis, hyperthermia, tachycardia, hyperreflexia) with this drug, especially if used in conjunction with other serotonin agents. ${ }^{57}$ In patients with a history of alcohol use, there is an increased risk of liver damage as preexisting hepatic damage may be present. ${ }^{55}$ In patients with controlled narrow-angle glaucoma, there may be an increased risk of mydriasis. Patients who are elderly or hypovolemic may develop hyponatremia with duloxetine. There have also been reports of the syndrome of inappropriate antidiuretic 
hormone secretion in patients taking duloxetine or other serotonin-norepinephrine reuptake inhibitors. Finally, if use is initiated during pregnancy, it should be delayed until the third trimester (pregnancy category C). ${ }^{55}$ Adverse effects that may occur commonly $(>10 \%)$ in patients include somnolence, dizziness, headaches, and insomnia. ${ }^{55}$ Possible cardiovascular effects include increase in blood pressure, orthostatic hypotension, syncope, and palpitations ${ }^{57}$ Possible gastrointestinal effects include nausea, xerostomia, diarrhea, and constipation. ${ }^{55}$ Other adverse effects reported in patients include hyperhidrosis, sexual dysfunction, diminished appetite, and urinary hesitancy. ${ }^{55}$

\section{Duloxetine for chronic musculoskeletal pain}

Duloxetine may have potential advantages for patients with chronic musculoskeletal pain and comorbid depression, and/ or anxiety, simply because in this situation clinicians may be able to treat more than one condition with single-agent therapy. However, duloxetine can be used effectively as monotherapy for patients purely with chronic musculoskeletal pain without any accompanying depression or anxiety. Although the precise mechanisms by which duloxetine contributes to alleviation of chronic musculoskeletal pain remain uncertain, it is likely that duloxetine may enhance descending inhibitory pain pathways by its actions of inhibiting the reuptake of serotonin and norepinephrine. It appears that there exist subgroups of patients with OA where central nervous system pain mechanisms (eg, loss of descending analgesic activity, central sensitization) may play a role in contributing to resting pain ${ }^{64,65}$ and movement-related pain. ${ }^{66}$

Quantitative sensory testing has revealed that OA patients have lower mechanical and thermal pain thresholds than healthy controls at sites close to affected joints, ${ }^{66-69}$ as well as at distant sites. ${ }^{70,71}$

Bajaj et al infused hypertonic saline into the tibialis anterior muscles of 14 OA patients and 14 age-matched and sex-matched controls. ${ }^{72}$ The OA patients reported muscle pain that was of increased intensity, covered larger pain areas (extending to the toes), and persisted for a longer duration than controls. ${ }^{72}$ Bajaj et al suggested that this was due to central pain mechanisms in the OA patients. ${ }^{72}$ Kosek and Ordeberg demonstrated that the loss of descending analgesic activity found in patients with hip OA was restored after hip surgery in most patients who reported significant clinical pain relief. ${ }^{71}$

In a study of 48 knee OA patients and 24 age-matched and sex-matched controls, OA patients exhibited central sensitization as well as greater loss of descending analgesic activity than healthy controls. ${ }^{68}$ The investigators measured (1) pressure pain thresholds; (2) spreading sensitization; (3) temporal summation to repeated pressure pain stimulation; (4) pain responses after intramuscular hypertonic saline; and (5) pressure pain modulation by heterotopic descending noxious inhibitory control (now referred to as conditioned pain modulation).$^{68}$ The patients were separated into strong/severe (Visual Analog Scale $\geq 6$ ) and mild/ moderate pain (Visual Analog Scale <6) groups. Pressure pain thresholds were measured from the peripatellar region, tibialis anterior, and extensor carpi radialis longus muscles before, during, and after descending noxious inhibitory control. Temporal summation to pressure was measured at the most painful site in the peripatellar region and over tibialis anterior. Patients with severely painful OA pain had significantly lower pressure pain threshold than controls. Significantly negative correlations between Visual Analog Scale and pressure pain threshold were found (eg, more pain, more sensitization) for all sites (eg, knee, leg, arm). OA patients showed a significant facilitation of temporal summation from both the knee and tibialis anterior, and had significantly less descending noxious inhibitory control as compared with controls. ${ }^{68}$

\section{Efficacy and safety of duloxetine}

Three major 12-week double-blind, placebo-controlled studies were conducted as part of efforts to demonstrate the safety and efficacy of duloxetine for patients with CLBP. The first two trials included flexible doses from $60 \mathrm{mg}$ to $120 \mathrm{mg}$ once daily, ${ }^{73,74}$ whereas the third study focused on fixed dose duloxetine (60 mg once daily). ${ }^{75}$

Although 404 patients were enrolled, only 267 patients completed the study. No significant differences existed between any dose of duloxetine and placebo on reduction in weekly mean 24-hour average pain at endpoint. Duloxetine $60 \mathrm{mg}$ was superior to placebo from week three to week eleven in relieving pain, but not at week twelve and week 13. Duloxetine $60 \mathrm{mg}$ demonstrated significant improvement on Patient Global Impression of Improvement, Roland-Morris Disability Questionnaire-24, Brief Pain Inventory (BPI) average pain and BPI average interference. Significantly more patients taking duloxetine $120 \mathrm{mg}(24.1 \%)$ discontinued because of AEs compared to placebo $(8.5 \%){ }^{73}$

In the first study, Skljarevski et al conducted a 13-week multicenter, randomized, double-blind, parallel, placebocontrolled trial that assessed the efficacy of duloxetine 20 , 
60 , and $120 \mathrm{mg}$ once daily compared with placebo on the reduction of pain in patients with $\mathrm{CLBP} .{ }^{73}$ In a second study, Skljarevski et al conducted a randomized double-blind trial that treated adult nondepressed patients who had nonneuropathic CLBP and a weekly mean 24-hour average pain score of $\geq 4$ at baseline (0-10 scale) with either duloxetine or placebo for 13 weeks. The dose of duloxetine during the first 7 weeks was 60-120 mg once daily. Compared with placebo-treated patients (least-squares mean change of -1.50), patients on duloxetine (least-squares mean change of -2.32 ) had a significantly greater reduction in the BPI 24-hour average pain score from baseline to endpoint $(P=0.004$ at week 13). Additionally, the duloxetine group significantly improved on Patient Global Impression of Improvement, Roland-Morris Disability Questionnaire-24, BPI pain severity, and BPI average interference weekly mean 24-hour average pain score, night pain, and worst pain. Significantly more patients in the duloxetine group (13.9\%), compared with placebo (5.8\%), discontinued because of AEs $(P=0.047)$. The most common treatmentemergent AEs in the duloxetine group included nausea, dry mouth, fatigue, diarrhea, hyperhidrosis, dizziness, and constipation. ${ }^{74}$

In a third study, Skljarevski et al conducted a randomized, double-blind, placebo-controlled study that assessed efficacy and safety of duloxetine in patients with CLBP. Adults $(\mathrm{N}=401)$ with nonneuropathic CLBP and an average pain intensity of 24 on an eleven-point numerical scale (BPI) were treated with either duloxetine $60 \mathrm{mg}$ once daily or placebo for 12 weeks. $^{75}$

Of the total patients randomized to placebo $(\mathrm{N}=203)$ or duloxetine $(\mathrm{N}=198), 76.8 \%$ and $74.2 \%$ of patients, respectively, completed the study. There was no statistically significant difference in overall discontinuation rates. Significantly $(P=0.02)$ more patients discontinued because of a lack of efficacy in the placebo treatment group (4.4\%) compared with the duloxetine group $(0.5 \%)$. In addition, significantly $(P=0.002)$ more patients discontinued because of AEs in the duloxetine treatment group (15.2\%) compared with the placebo group (5.4\%). ${ }^{75}$

Compared with placebo-treated patients, duloxetinetreated patients reported a significantly greater reduction in BPI average pain $(P=0.001)$. Similarly, duloxetinetreated patients reported significantly greater improvements in Patient Global Impression of Improvement, BPI pain severity, BPI average interference, 50\% response rates, and some health outcomes. The Roland-Morris Disability Questionnaire-24 and 30\% response rate showed numerical improvements with duloxetine treatment. Significantly more patients in the duloxetine group (15.2\%), compared to the placebo group (5.4\%), discontinued because of AEs $(P=0.002)$. Nausea and dry mouth were the most common treatment-emergent AEs with rates significantly higher in duloxetine-treated patients. ${ }^{75}$

Karp et al conducted an open-label duloxetine and care management therapy in the overall management of older adults with comorbid major depressive disorder and CLBP. ${ }^{76}$ Most $(93.3 \%, \mathrm{n}=28)$ had a significant pain response. The mean time to depression remission was 7.6 (standard error $=0.6$ ) weeks. The mean time to pain response was 2.8 (standard error $=0.5$ ) weeks. There were significant improvements in mental health-related quality of life, anxiety, sleep quality, somatic complaints, and both self-efficacy for pain management and for coping with symptoms. $^{76}$

Two pivotal studies were conducted as a regulatory requirement to assess the efficacy and safety of duloxetine in patients with chronic pain due to OA of the knee. ${ }^{77,78}$ Chappell et al conducted a 13-week randomized, placebocontrolled trial of duloxetine (60-120 mg/day) in 174 patients ( $74.9 \%$ of the total 231 who enrolled) with significant knee pain from OA. ${ }^{77}$ Duloxetine was superior to placebo on the primary efficacy measure (weekly mean 24-hour average pain scores) beginning at week one and continuing through the treatment period $(P \leq 0.05)$. There was also a significant improvement in the Western Ontario and McMaster University OA Index (WOMAC) physical functioning subscale and several other secondary outcomes. ${ }^{77}$ Path analysis demonstrated that $95 \%$ of the effect was due to analgesic efficacy rather than any reduction in symptoms of depression or anxiety. When dose differences were measured from baseline to end point, the 120-mg dose was statistically better than the 60-mg dose, but when response rates defined by a $30 \%$ and $50 \%$ reduction in pain were used, no dose differential was found. There was no difference in dropout rate between placebo and duloxetine groups. There was no difference in serious AEs between the duloxetine (49.5\%) and placebo (40.8\%) groups. ${ }^{77}$

Chappell et al conducted another 13-week randomized, double-blind, placebo-controlled trial in 204 patients (of the total 206 patients enrolled) meeting the American College of Rheumatology clinical and radiographic criteria for OA of the knee. ${ }^{78}$ Patients treated with duloxetine had significantly $(P \leq 0.001)$ greater improvement at all time points on BPI average pain and had significantly greater improvement on BPI pain severity ratings $(P \leq 0.05)$, WOMAC total 
( $P=0.044)$ and physical functioning scores $(P=0.016)$, and Clinical Global Impressions-Severity $(P=0.009)$ at the study endpoint. Frequency of treatment-emergent nausea, constipation, and hyperhidrosis were significantly higher in the duloxetine group $(P \leq 0.05)$. Significantly more duloxetine-treated patients discontinued the trial because of AEs $(P=0.002){ }^{78}$ Treatment with duloxetine $60-120 \mathrm{mg}$ once daily was associated with significant pain reduction and improved function in patients with pain due to OA of the knee. ${ }^{78}$

Hochberg et al pooled data from two 13-week randomized, double-blind, placebo-controlled trials ${ }^{77,78}$ comparing duloxetine $60-120 \mathrm{mg} /$ day with placebo in patients with symptomatic OA of the knee. ${ }^{79}$ Treatment response was determined according to the Outcome Measures in Rheumatoid Arthritis Clinical Trials-OA Research Society International responder index, $\geq 30 \%$ pain reduction, $\geq 50 \%$ pain reduction, and minimal clinically important improvement and patient acceptable symptom state for pain and function. Duloxetine-treated patients were $33 \%$ more likely to experience a response than placebo-treated patients $(P<0.001$, number needed to treat $[\mathrm{NNT}]=6)$. A significantly greater percentage of duloxetine-treated patients, compared with placebotreated patients, reported $\geq 30 \%$ improvement in pain from baseline to endpoint $(P<0.001, \mathrm{NNT}=5)$ and $\geq 50 \%$ improvement in pain relative to baseline $(P<0.001$, NNT $=7$ ). The duloxetine-treated patients were also more likely to fulfill minimal clinically important improvement criteria for pain $(P<0.001$, NNT $=6)$ and function $(P<0.001, \mathrm{NNT}=7)$, and to achieve patient acceptable symptom state for pain $(P<0.001, \mathrm{NNT}=6)$ and function $(P=0.009, \mathrm{NNT}=9)$. More duloxetine-treated patients compared with placebo-treated patients experienced at least one treatment-emergent $\mathrm{AE}(P=0.003$, number needed to harm $=8) .{ }^{79}$

Sullivan et al performed a single-blind, placebo run-in trial of 60-90 mg duloxetine in 25 subjects with activitylimiting OA pain. Each subject received 2 weeks of placebo followed by 10 weeks of duloxetine. The primary outcome was reduction in average pain intensity between 2-12 weeks for subjects completing the trial..$^{80}$ Average pain on the BPI was 5.7 at baseline, 4.8 after the 2-week placebo run-in, and 3.5 at 12 weeks for the 17 patients completing the trial (28\% decrease between 2 weeks and 12 weeks, $P=0.122$ ). Eight of the 15 study completers who had nonmissing BPI results (53\%) reported at least 30\% pain reduction between 2 weeks and 12 weeks. The WOMAC pain score at baseline was $2.3,1.8$ after 2 weeks, and 1.3 after 12 weeks $(30 \%$ decrease between 2 weeks and 12 weeks, $P=0.018$ ). Ten of 17 patients (59\%) reported at least 30\% pain relief between 2 weeks and 12 weeks on the WOMAC ${ }^{64}$ Duloxetine did not significantly reduce pain intensity on the BPI, but did improve pain intensity and self-reported function on the WOMAC. ${ }^{80}$

Therapy with duloxetine has also been reported for other chronic musculoskeletal conditions. Two mentally healthy young Asian women aged 32 and 27 years, each with tennis elbow of about 18 months duration, continued to suffer pain despite treatment with analgesics, local steroid injections, physiotherapy, cryotherapy, ultrasound, and surgical release, among other interventions. Both showed substantial improvement within 4-6 weeks of receiving monotherapy with duloxetine $60 \mathrm{mg} /$ day. Both were pain-free with continued treatment at a 6-month follow-up. ${ }^{81}$

Brunton et al analyzed data from all placebo-controlled trials of duloxetine completed as of December 2008 for adverse effects. The 52 studies included 17,822 patients (duloxetine, $\mathrm{N}=10,326$; placebo, $\mathrm{N}=7496$ ) with major depressive disorder, generalized anxiety disorder, diabetic peripheral neuropathic pain, fibromyalgia, OA knee pain, CLBP, and lower urinary tract disorders. ${ }^{82}$ The overall treatment-emergent $\mathrm{AE}$ rate was $57.2 \%$ for placebotreated patients and $72.4 \%$ for duloxetine-treated patients $(P \leq 0.001)$. Patients with OA knee pain had the lowest treatment-emergent $\mathrm{AE}$ rate (placebo $36.7 \%$ versus duloxetine $50.2 \%, P \leq 0.01$ ), while patients with fibromyalgia had the highest rate (placebo $80.0 \%$ versus duloxetine $89.0 \%$, $P \leq 0.001)$. The most common treatment-emergent AE for all indications was nausea (placebo $7.2 \%$ versus duloxetine $23.4 \%, P \leq 0.001$ ), which was predominantly mild to moderate in severity. ${ }^{82}$

As far as AEs for the treatment of musculoskeletal pain in placebo-controlled clinical trials, the overall discontinuation rates due to AEs were $16.3 \%$ versus $5.6 \%$ for OA and $16.5 \%$ versus $6.3 \%$ for CLBP (Table 1). The common AEs reported as a reason for discontinuation and considered to be drug related were nausea ( $2.9 \%$ versus $0.8 \%)$ and asthenia $(1.3 \%$ versus $0 \%)$ for $\mathrm{OA}$ and nausea $(3.0 \%$ versus $0.7 \%)$ and somnolence $(1.0 \%$ versus $0 \%)$ for CLBP.

Frakes et al conducted a 10 -week randomized, doubleblind, placebo controlled trial in efforts to determine the efficacy, tolerability, and safety of duloxetine when added to oral NSAIDs in patients with OA of the knee with pain of moderate or greater severity (score of 4-6 on Numerical Rating Scale-11). ${ }^{84}$ It was a flexible-dose (duloxetine 
Table I Duloxetine adverse events for treatment of musculoskeletal pain

\begin{tabular}{|c|c|c|}
\hline $\begin{array}{l}\text { Chronic low } \\
\text { back pain }\end{array}$ & $\begin{array}{l}\text { Duloxetine } \\
20 / 60 / 120 \mathrm{mg} / \mathrm{day} \\
(\mathrm{N}=600)\end{array}$ & $\begin{array}{l}\text { Placebo } \\
(N=44 I)\end{array}$ \\
\hline Nausea & $16.2 \%$ & $2.9 \%$ \\
\hline Dry mouth & $8.5 \%$ & $2.0 \%$ \\
\hline Insomnia & $8.0 \%$ & $3.6 \%$ \\
\hline Somnolence & $7.7 \%$ & $1.4 \%$ \\
\hline Constipation & $7.3 \%$ & $2.0 \%$ \\
\hline Dizziness & $6.3 \%$ & $1.8 \%$ \\
\hline Fatigue & $6.3 \%$ & $0.9 \%$ \\
\hline Osteoarthritis & $\begin{array}{l}\text { Duloxetine } \\
60 / 120 \mathrm{mg} / \mathrm{day} \\
(\mathrm{N}=239)\end{array}$ & $\begin{array}{l}\text { Placebo } \\
(N=248)\end{array}$ \\
\hline Nausea & $8.4 \%$ & $2.0 \%$ \\
\hline Fatigue & $6.7 \%$ & $0.8 \%$ \\
\hline Constipation & $5.9 \%$ & $0.8 \%$ \\
\hline
\end{tabular}

Notes: Most common adverse events reported at a rate of $\geq 5 \%$ with duloxetine and at least twice the rate of placebo. Cymbalta ${ }^{\circledR 83}$

$60 / 120 \mathrm{mg} /$ day), placebo-controlled trial that enrolled adult outpatients who had persistent moderate or greater pain ( $\geq 4$ on Numerical Rating Scale-11) due to OA of the knee despite, per protocol, having received optimized oral NSAID therapy (specific drug, dose, and frequency at investigator discretion). A total of 524 patients randomly received duloxetine $60 / 120 \mathrm{mg} /$ day $(\mathrm{N}=264)$ or placebo $(\mathrm{N}=260)$. In total, $74 \%$ of the patients completed the study. ${ }^{83}$ Duloxetine-treated patients had significantly greater pain reduction at week eight $(P<0.001)$ than placebotreated patients. In addition, relative to placebo at week eight, duloxetine-treated patients had significant improvements in physical function as measured by the WOMAC $(P<0.001)$ and Patient Global Impression of Improvement $(P<0.001)$. Compared to placebo, significantly more nausea, dry mouth, constipation, fatigue, and decreased appetite were reported by patients taking duloxetine (each $P<0.05$ ). ${ }^{84}$ Frakes et al concluded that duloxetine added to oral NSAID therapy provided additional significant pain reduction, improved function, and patient-rated impression of improvement. AEs were consistent with those seen in previous duloxetine trials. The short duration of the study may not reflect the long-term efficacy and safety of NSAID/duloxetine cotherapy ${ }^{84}$

\section{Summary}

Musculoskeletal pain remains one of the most common pain complaints brought to health care providers. The management of various musculoskeletal conditions is extremely complex, controversial, and involves nonpharmacologic, pharmacologic and interventional approaches. Pharmacologic approaches may include acetaminophen, NSAIDs, muscle relaxants, topical NSAIDs, topical lidocaine, topical capsaicin, opioids/ dual mechanism agents (tramadol, tapentadol) and duloxetine. Duloxetine is a serotonin-norepinephrine reuptake inhibitor that has been shown to be safe and efficacious for painful musculoskeletal conditions. In the three trials of duloxetine for low back pain, the rate of discontinuation of duloxetine as a result of side effects compared with placebo was: $24.1 \%$ versus $8.5 \% ;^{73} 13.9 \%$ versus $5.8 \%{ }^{74}$ - and $15.2 \%$ versus 5.4\%. ${ }^{75}$ The most common treatment-emergent AEs were nausea fatigue, diarrhea, hyperhidrosis, dizziness, constipation, and dry mouth. ${ }^{73,74,75}$ In the OA trials, the rate of discontinuation of duloxetine as a result of side effects compared with placebo was: $13.5 \%$ versus $5.8 \%{ }^{77}$ and $18.8 \%$ versus $5.4 \%{ }^{75}(P=0.002)^{75}$ The role of duloxetine for musculoskeletal conditions is evolving. Although there are no studies that would currently support that duloxetine is particularly well suited for any specific subgroups of patients with OA, the authors propose that duloxetine be studied in subgroups of OA patients with joints without overt signs of inflammation and especially in more "proximally located joints" (eg, knees, hips, shoulders, elbows, sacroiliac joints). They also propose that a subset of patients with OA who use pain quality descriptors suggestive of neuropathic pain (eg, heat, pins and needles, tingling) to describe their discomfort ${ }^{85}$ may be particularly well suited to respond to duloxetine therapy. Furthermore, it may even be conceivable in the future that the analgesic response to certain interventions (eg, transcutaneous electrical nerve stimulation) ${ }^{86}$ may help "tease out"/identify specific subpopulations of patients with chronic musculoskeletal pain (eg, OA) that may respond particularly well to duloxetine. Also, patients with inefficient conditional pain modulation may respond better to duloxetine. ${ }^{87}$ Furthermore, it remains to be seen if duloxetine combined with another analgesic agent may be useful for patients with painful musculoskeletal conditions who do not respond satisfactorily to monotherapy.

\section{Acknowledgment}

The authors would like to acknowledge Pya Seidner for her enormous efforts toward the preparation of this manuscript.

\section{Disclosure}

The authors report no conflicts of interest in this work. The authors confirm that they have permission to reproduce any 
copyrighted material. This manuscript has been read and approved by all authors. This paper is unique and not under consideration by any other publication and has not been published elsewhere.

\section{References}

1. Altman RD, Smith HS. Opioid therapy for osteoarthritis and chronic low back pain. Postgrad Med. 2010;122(6):87-97.

2. Braden JB, Fan MY, Edlund MJ, Martin BC, DeVries A, Sullivan MD. Trends in use of opioids by noncancer pain type 2000-2005 among Arkansas Medicaid and HealthCore enrollees: results from the TROUP study. J Pain. 2008;9(11):1026-1035.

3. Sullivan MD, Edlund MJ, Fan MY, DeVries A, Braden JB, Martin BC. Trends in use of opioids for non-cancer pain conditions 2000-2005 in commercial and Medicaid insurance plans: the TROUP study. Pain. 2008;138(2):440-449.

4. Chan KW, Ngai HY, Ip KK, Lam KH, Lai WW. Co-morbidities of patients with knee osteoarthritis. Hong Kong Med J. 2009;15(3) 168-172.

5. Reeuwijk KG, de Rooij M, van Dijk GM, Veenhof C, Steuktjens MP, Dekker J. Osteoarthritis of the hip or knee: which coexisting disorders are disabling? Clin Rheumatol. 2010;29(7):739-747.

6. Bower WA, Johns M, Margolis HS, Williams IT, Bell BP. Populationbased surveillance for acute liver failure. Am J Gastroenterol. 2007;102(11):2459-2463.

7. Chun LJ, Tong MJ, Busuttil RW, Hiatt JR. Acetaminophen hepatotoxicity and acute liver failure. J Clin Gastroenterol. 2009;43(4): 342-349.

8. Lee C, Straus WL, Balshaw R, Barlas S, Vogel S, Schnitzer TJ. A comparison of the efficacy and safety of nonsteroidal antiinflammatory agents versus acetaminophen in the treatment of osteoarthritis: a meta-analysis. Arthritis Rheum. 2004;51(5):746-754.

9. Watkins PB, Kaplowitz N, Slattery JT, et al. Aminotransferase elevations in healthy adults receiving 4 grams of acetaminophen daily: a randomized controlled trial. JAMA. 2006;296(1):87-93.

10. Puenpatom RA, Victor TW. Increased prevalence of metabolic syndrome in individuals with osteoarthritis: an analysis of NHANES III data. Postgrad Med. 2009;121(6):9-20.

11. Chou R, Qaseem A, Snow V, et al. Diagnosis and treatment of low back pain: a joint clinical practice guideline from the American College of Physicians and the American Pain Society. Ann Intern Med. 2007;147(7):478-491.

12. Institute for Clinical Systems Improvement. Adult Low Back Pain. Bloomington, MN: Institute for Clinical Systems Improvement; 2008.

13. Michigan Quality Improvement Consortium. Management of Acute Low Back Pain. Southfield, MI: Michigan Quality Improvement Consortium; 2008.

14. National Collaborating Centre for Chronic Conditions. Osteoarthritis: The Care and Management of Osteoarthritis in Adults. London: Royal College of Physicians; 2008.

15. Zhang W, Doherty M, Leeb BF, et al. EULAR evidence based recommendations for the management of hand osteoarthritis: report of a Task Force of the EULAR Standing Committee for International Clinical Studies Including Therapeutics (ESCISIT). Ann Rheum Dis. 2007;66(3):377-388.

16. Zhang W, Moskowitz RW, Nuki G, et al. OARSI recommendations for the management of hip and knee osteoarthritis, Part II: OARSI evidence-based, expert consensus guidelines. Osteoarthritis Cartilage. 2008;16(2):137-162

17. Chou R, Shekelle P. Will this patient develop persistent disabling low back pain? JAMA. 2010;303(13):1295-1302.

18. Towheed TE, Maxwell L, Judd MG, Catton M, Hochberg MC, Wells G. Acetaminophen for osteoarthritis. Cochrane Database Syst Rev. 2006;1:CD004257.
19. Kuehn BM. FDA focuses on drugs and liver damage: labeling and other changes for acetaminophen. JAMA. 2009;302(4):369-371.

20. Bjordal JM, Ljunggren AE, Klovning A, Slordal L. Non-steroidal anti-inflammatory drugs, including cyclo-oxygenase- 2 inhibitors, in osteoarthritic knee pain: meta-analysis of randomised placebo controlled trials. BMJ. 2004;329(7478):1317.

21. Fendrick AM, Greenberg BP. A review of the benefits and risks of nonsteroidal anti-inflammatory drugs in the management of mildto-moderate osteoarthritis. Osteopath Med Prim Care. 2009;3:1.

22. Hippisley-Cox J, Coupland C, Logan R. Risk of adverse gastrointestinal outcomes in patients taking cyclo-oxygenase- 2 inhibitors or conventional non-steroidal anti-inflammatory drugs: population based nested case-control analysis. BMJ. 2005;331(7528):1310-1316.

23. Kearney PM, Baigent C, Godwin J, Halls H, Emberson JR, Patrono C. Do selective cyclo-oxygenase-2 inhibitors and traditional non-steroidal antiinflammatory drugs increase the risk of atherothrombosis? Meta-analysis of randomised trials. BMJ. 2006;332(7553):1302-1308.

24. Evans JM, McGregor E, McMahon AD, et al. Non-steroidal antiinflammatory drugs and hospitalization for acute renal failure. QJM. 1995;88(8):551-557.

25. Antman EM, Bennett JS, Daugherty A, et al. Use of nonsteroidal antiinflammatory drugs: an update for clinicians: a scientific statement from the American Heart Association. Circulation. 2007;115(12): 1634-1642.

26. Cheetham TC, Levy G, Niu F, Bixler F. Gastrointestinal safety of nonsteroidal antiinflammatory drugs and selective cyclooxygenase- 2 inhibitors in patients on warfarin. Ann Pharmacother. 2009;43(11):1765-1773.

27. Farkouh ME, Greenberg JD, Jeger RV, et al. Cardiovascular outcomes in high risk patients with osteoarthritis treated with ibuprofen, naproxen or lumiracoxib. Ann Rheum Dis. 2007;66(6):764-770.

28. American Geriatrics Society Panel on Pharmacological Management of Persistent Pain in Older Persons. Pharmacological management of persistent pain in older persons. J Am Geriatr Soc. 2009;57(8): 1331-1346.

29. Kienzler JL, Gold M, Nollevaux F. Systemic bioavailability of topical diclofenac sodium gel 1\% versus oral diclofenac sodium in healthy volunteers. J Clin Pharmacol. 2010;50(1):50-61.

30. Altman RD, Dreiser RL, Fisher CL, Chase WF, Dreher DS, Zacher J. Diclofenac sodium gel in patients with primary hand osteoarthritis: a randomized, double-blind, placebo-controlled trial. J Rheumatol. 2009;36(9):1991-1999.

31. Barthel HR, Haselwood D, Longley S 3rd, Gold MS, Altman RD. Randomized controlled trial of diclofenac sodium gel in knee osteoarthritis. Semin Arthritis Rheum. 2009;39(3):203-212.

32. Simon LS, Grierson LM, Naseer Z, Bookman AA, Zev Shainhouse J. Efficacy and safety of topical diclofenac containing dimethyl sulfoxide (DMSO) compared with those of topical placebo, DMSO vehicle and oral diclofenac for knee osteoarthritis. Pain. 2009;143(3): 238-245.

33. Baraf HS, Gold MS, Clark MB, Altman RD. Safety and efficacy of topical diclofenac sodium 1\% gel in knee osteoarthritis: a randomized controlled trial. Phys Sportsmed. 2010;38(2):19-28.

34. Singh G, Fort JG, Goldstein JL, et al. Celecoxib versus naproxen and diclofenac in osteoarthritis patients: SUCCESS-I Study. Am J Med. 2006;119(3):255-266.

35. LIDODERM, lidocaine path 5\% [package insert.] Chadds Ford, PA; Endo Pharmaceuticals; 2010.

36. Gammaitoni AR, Galer BS, Onawola R, Jensen MP, Argoff CE. Lidocaine patch $5 \%$ and its positive impact on pain qualities in osteoarthritis: results of a pilot 2-week, open-label study using the Neuropathic Pain Scale. Curr Med Res Opin. 2004;20 Suppl 2: S13-S19.

37. Kivitz A, Fairfax M, Sheldon EA, et al. Comparison of the effectiveness and tolerability of lidocaine patch $5 \%$ versus celecoxib for osteoarthritisrelated knee pain: post hoc analysis of a 12 week, prospective, randomized, active-controlled, open-label, parallel-group trial in adults. Clin Ther. 2008;30(12):2366-2377. 
38. Argoff CE, Galer BS, Jensen MP, Oleka N, Gammaitoni AR. Effectiveness of the lidocaine patch $5 \%$ on pain qualities in three chronic pain states: assessment with the Neuropathic Pain Scale. Curr Med Res Opin. 2004;20 Suppl 2:S21-S28.

39. Galer BS, Gammaitoni AR, Oleka N, Jensen MP, Argoff CE. Use of the lidocaine patch $5 \%$ in reducing intensity of various pain qualities reported by patients with low-back pain. Curr Med Res Opin. 2004;20 Suppl 2:S5-S12.

40. Gimbel J, Linn R, Hale M, Nicholson B. Lidocaine patch treatment in patients with low back pain: results of an open-label, nonrandomized pilot study. Am J Ther. 2005;12(4):311-319.

41. Ethgen O, Bruyere O, Richy F, Dardennes C, Reginster JY. Health-related quality of life in total hip and total knee arthroplasty. A qualitative and systematic review of the literature. J Bone Joint Surg Am. 2004;86-A(5):963-974.

42. Virolainen P, Aro HT. High tibial osteotomy for the treatment of osteoarthritis of the knee: a review of the literature and a meta-analysis of follow-up studies. Arch Orthop Trauma Surg. 2004;124(4):258-261.

43. Bravo CJ, Rizzo M, Hormel KB, Beckenbaugh RD. Pyrolytic carbon proximal interphalangeal joint arthroplasty: results with minimum two-year follow-up evaluation. J Hand Surg Am. 2007;32(1):1-11.

44. Field J. Two to five year follow-up of the LPM ceramic coated proximal interphalangeal joint arthroplasty. J Hand Surg Eur Vol. 2008;33(1):38-44.

45. Patt S, McDiarmid T. Tramadol addiction. J Fam Pract. 2005;54(4):356.

46. Pollice R, Casacchia M, Bianchini V, Mazza M, Conti CM, Roncone R. Severe tramadol addiction in a 61 year-old woman without a history of substance abuse. Int J Immunopathol Pharmacol. 2008;21(2):475-476.

47. Woody GE, Senay EC, Geller A, et al. An independent assessment of MEDWatch reporting for abuse/dependence and withdrawal from Ultram (tramadol hydrochloride). Drug Alcohol Depend. 2003;72(2):163-168.

48. Inciardi JA, Cicero TJ, Munoz A, et al. The diversion of Ultram, Ultracet, and generic tramadol HCL. J Addict Dis. 2006;25(2):53-58.

49. Cicero TJ, Inciardi JA, Adams EH, et al. Rates of abuse of tramadol remain unchanged with the introduction of new branded and generic products: results of an abuse monitoring system, 1994-2004. Pharmacoepidemiol Drug Saf. 2005;14(12):851-859.

50. Senay EC, Adams EH, Geller A, et al. Physical dependence on Ultram (tramadol hydrochloride): both opioid-like and atypical withdrawal symptoms occur. Drug Alcohol Depend. 2003;69(3):233-241.

51. Lanier RK, Lofwall MR, Mintzer MZ, Bigelow GE, Strain EC. Physical dependence potential of daily tramadol dosing in humans. Psychopharmacology (Berl). 2010;211(4):457-466.

52. Zhang W, Nuki G, Moskowitz RW, et al. OARSI recommendations for the management of hip and knee osteoarthritis: part III: changes in evidence following systematic cumulative update of research published through January 2009. Osteoarthritis Cartilage. 2010;18(4):476-499.

53. National Collaborating Centre for Primary Care. Low Back Pain. Early Management of Persistent Non-specific Low Back Pain. London: Royal College of Physicians; 2009.

54. Airaksinen O, Brox JI, Cedraschi C, et al. Chapter 4. European guidelines for the management of chronic nonspecific low back pain. Eur Spine J. 2006;15 Suppl 2:S192-S300.

55. Smith HS, Barkin RL. Fibromyalgia syndrome: a discussion of the syndrome and pharmacotherapy. Am Ther. 2010;17(4):418-439.

56. Stahl SM, Grady MM, Moret C, Briley M. SNRIs: their pharmacology, clinical efficacy, and tolerability in comparison with other classes of antidepressants. CNS Spectr. 2005;10(9):732-747.

57. Hansten PD, Horn JR. The Top 100 Drug Interactions: A Guide to Patient Management. Freeland, WA: H\&H Publications LLP; 2010.

58. Knadler MP, Lobo E, Chappell J, Bergstrom R. Duloxetine: clinical pharmacokinetics and drug interactions. Clin Pharmacokinet. 2011; 50(5):281-294.
59. Wickersham RM, editor. Drug facts and comparisons. E-answers Wolter Kluwer. Health Inc; Referred 2010.

60. Barkin RL. Duloxetine: a pharmacological overview. Pain Med Network. 2007;22:8-11.

61. Curran MP. Duloxetine: in patients with fibromyalgia. Drugs. 2009;69(9):1217-1227.

62. Relling MV, Lin JS, Ayers GD, Evans WE. Racial and gender differences in N-acetyltransferase, xanthine oxidase, and CYP1A2 activities. Clin Pharmacol Ther. 1992;52(6):643-658.

63. Schrenk D, Brockmeier D, Morike K, Bock KW, Eichelbaum M. A distribution study of CYP1A2 phenotypes among smokers and non-smokers in a cohort of healthy Caucasian volunteers. Eur J Clin Pharmacol. 1998;53(5):361-367.

64. Mease PJ, Hanna S, Frakes EP, Altman RD. Pain mechanisms in osteoarthritis: understanding the role of central pain and current approaches to its treatment. $J$ Rheumatol. 2011;38(8):1546-1551.

65. Lee YC, Nassikas NJ, Clauw DJ. The role of the central nervous system in the generation and maintenance of chronic pain in rheumatoid arthritis, osteoarthritis and fibromyalgia. Arthritis Res Ther. 2011; 13(2):211.

66. Farrell MJ, Gibson SJ, McMeeken JM, Helme RD. Increased movement pain in osteoarthritis of the hands is associated with A beta-mediated cutaneous mechanical sensitivity. J Pain. 2000;1(3):229-242.

67 . Wessel J. The reliability and validity of pain threshold measurements in osteoarthritis of the knee. Scand J Rheumatol. 1995;24(4): $238-242$.

68. Arendt-Nielsen L, Nie H, Laursen MB, et al. Sensitization in patients with painful knee osteoarthritis. Pain. 2010;149(3):573-581.

69. Gwilym SE, Keltner JR, Warnaby CE, et al. Psychophysical and functional imaging evidence supporting the presence of central sensitization in a cohort of osteoarthritis patients. Arthritis Rheum. 2009;61(9):1226-1234.

70. O'Driscoll SL, Jayson MI. Pain threshold analysis in patients with osteoarthrosis of hip. Br Med J. 1974;3(5933):714-715.

71. Kosek E, Ordeberg G. Lack of pressure pain modulation by heterotopic noxious conditioning stimulation in patients with painful osteoarthritis before, but not following, surgical pain relief. Pain. 2000;88(1):69-78.

72. Bajaj P, Bajaj P, Graven-Nielsen T, Arendt-Nielsen L. Osteoarthritis and its association with muscle hyperalgesia: an experimental controlled study. Pain. 2001;93(2):107-114.

73. Skljarevski V, Ossanna M, Liu-Seifert H, et al. A double-blind, randomized trial of duloxetine versus placebo in the management of chronic low back pain. Eur J Neurol. 2009;16(9):1041-1048.

74. Skljarevski V, Desaiah D, Liu-Seifert H, et al. Efficacy and safety of duloxetine in patients with chronic low back pain. Spine (Phila Pa 1976). 2010;35(13):E578-E585.

75. Skljarevski V, Zhang S, Desaiah D, et al. Duloxetine versus placebo in patients with chronic low back pain: a 12-week, fixed-dose, randomized, double-blind trial. J Pain. 2010;11(12):1282-1290.

76. Karp JF, Weiner DK, Dew MA, Begley A, Miller MD, Reynolds CF 3rd. Duloxetine and care management treatment of older adults with comorbid major depressive disorder and chronic low back pain: results of an open-label pilot study. Int J Geriatr Psychiatry. 2010;25(6): 633-642.

77. Chappell AS, Ossanna MJ, Liu-Seifert H, et al. Duloxetine, a centrally acting analgesic, in the treatment of patients with osteoarthritis knee pain: a 13-week, randomized, placebo-controlled trial. Pain. 2009;146(3):253-260.

78. Chappell AS, Desaiah D, Liu-Seifert H, et al. A double-blind, randomized, placebo-controlled study of the efficacy and safety of duloxetine for the treatment of chronic pain due to osteoarthritis of the knee. Pain Pract. 2011;11(1):33-41.

79. Hochberg MC, Wohlreich M, Gaynor P, Hanna S, Risser R. Clinically relevant outcomes based on analysis of pooled data from 2 trials of duloxetine in patients with knee osteoarthritis. J Rheumatol. 2012;39(2):352-358. 
80. Sullivan MD, Bentley S, Fan MY, Gardner G. A single-blind, placebo run-in study of duloxetine for activity-limiting osteoarthritis pain. J Pain. 2009;10(2):208-213.

81. Wani ZA, Dhar SA, Butt MF, Rather YH, Sheikh S. Duloxetine in treatment of refractory chronic tennis elbow: two case reports. J Med Case Reports. 2008;2:305.

82. Brunton S, Wang F, Edwards SB, et al. Profile of adverse events with duloxetine treatment: a pooled analysis of placebo-controlled studies. Drug Saf. 2010;33(5):393-407.

83. Cymbalta ${ }^{\mathbb{B}}$ full prescribing information; data on file with Lily Research Laboratories, 2011.

84. Frakes EP, Risser RC, Ball TD, Hochberg MC, Wohlreich MM. Duloxetine added to oral nonsteroidal anti-inflammatory drugs for treatment of knee pain due to osteoarthritis: results of a randomized, double-blind, placebo-controlled trial. Curr Med Res Opin. 2011;27(12): 2361-2372.
85. Hochman JR, French MR, Bermingham SL, Hawker GA. The nerve of osteoarthritis pain. Arthritis Care Res (Hoboken). 2010;62(7):1019-1023.

86. Beckwee D, De Hertogh W, Lievens P, Bautmans I, Vaes P. Effect of TENS on pain in relation to central sensitization in patients with osteoarthritis of the knee: study protocol for a randomized controlled trial. Trials. 2012;13(1):21.

87. Yarnitzky D, Granot M, Mahman-Averbuch H, Khamaisi M, GranovskyY. Conditioned pain modulation predicts duloxetine efficacy in painful diabetic neuropathy. Pain.2012:153(6):1193-1198.

\section{Publish your work in this journal}

Therapeutics and Clinical Risk Management is an international, peerreviewed journal of clinical therapeutics and risk management, focusing on concise rapid reporting of clinical studies in all therapeutic areas, outcomes, safety, and programs for the effective, safe, and sustained use of medicines. This journal is indexed on PubMed Central, CAS,
EMBase, Scopus and the Elsevier Bibliographic databases. The manuscript management system is completely online and includes a very quick and fair peer-review system, which is all easy to use. Visit http://www.dovepress.com/testimonials.php to read real quotes from published authors.

Submit your manuscript here: http://www.dovepress.com/therapeutics-and-clinical-risk-management-journal 